Research Paper

\title{
YAP1 regulates ABCG2 and cancer cell side population in human lung cancer cells
}

\author{
Yuyuan Dai ${ }^{1, *}$, Shu Liu ${ }^{1, *}$, Wen-Qian Zhang ${ }^{1,2}$, Yi-Lin Yang ${ }^{1}$, Phillip Hang ${ }^{1}$, Hui \\ Wang $^{1}$, Li Cheng ${ }^{1}$, Ping-Chih Hsu ${ }^{1}$, Yu-Chen Wang ${ }^{1}$, Zhidong Xu ${ }^{1}$, David M. Jablons ${ }^{1}$, \\ Liang You ${ }^{1}$ \\ ${ }^{1}$ Thoracic Oncology Laboratory, Department of Surgery, Comprehensive Cancer Center, University of California, San \\ Francisco, CA, USA \\ ${ }^{2}$ Department of Thoracic Surgery, Beijing Chao-Yang Hospital, Affiliated with Capital University of Medical Science, Beijing, \\ People's Republic of China \\ *These authors contributed equally to this work
}

Correspondence to: Liang You, email: Liang.you@ucsfmedctr.org

Keywords: ABCG2, YAP1, side population, cancer stem cells, lung cancer

Received: June 04, $2016 \quad$ Accepted: November 21, $2016 \quad$ Published: November 29, 2016

\section{ABSTRACT}

A small population of cancer cells called cancer-initiating cells or cancer stem cells (CSCs) are involved in drug resistance, metastasis, and cancer relapse. Finding pathways that regulate CSC is very important for clinical therapy. ATP-binding cassette sub-family G member 2 (ABCG2) plays a role in side population (SP) cell formation and contributes to chemotherapy resistance in common forms of cancer. Yes-associated protein 1 (YAP1) is a major transcriptional effector of the Hippo pathway, which plays important roles in organ size control and tumorigenesis. In this study, we found ABCG2 and YAP1 were both overexpressed in lung cancer SP cells. Disruption of YAP1 expression by siRNA attenuated the expression of ABCG2 transcript and significantly reduced the percentage of SP cells and sphere formation in lung cancer cells. Overexpression of YAP1 in lung cancers led to an increase in ABCG2 expression and increased the percentage of SP cells. However, overexpression of YAP1 in purified non-SP cells did not increase ABCG2 expression and the percentage of SP cells, which may be due to the inhibition of YAP activity through phosphorylation. YAP1 directly transcriptionally regulated ABCG2 by binding to the promoter of ABCG2. Moreover, the YAP1 inhibitor verteporfin and YAP1 siRNA downregulated ABCG2 level through inhibition of YAP1 in lung cancer cells and sensitized them to the chemotherapy drug doxorubicin. Our study adds a new function for YAP1 that may be relevant to drug resistance and cancer therapy through regulation of ABCG2 and side population cell formation in lung cancer.

\section{INTRODUCTION}

Accumulating evidence indicates that tumors are a heterogeneous mixture containing mostly non-stem cells and a small subpopulation of cancer stem cells (CSCs) [1]. Despite the self-renewal and tumor initiation ability of CSCs, they can also export certain toxic compounds resistant to many chemotherapeutic agents and cause tumor relapse [2]. The compound efflux ability of CSCs comes from the increased expression of ATP-binding cassette $(\mathrm{ABC})$ transporters within the cell membrane and serves as the basis of an important flow-cytometry-based cell-sorting assay called the side population (SP) assay [3-6]. The SP assay is characterized by the differential potential of cells to efflux a DNA-binding dye, Hoechst 33342. The high efflux ability of CSCs leads to a low retention of Hoechst 33342 fluorescent signal in these cells, which reside at the low-left corner in flow cytometry analysis and thus are also known as side population (SP) cells or cancer stemlike cells [7]. The SP assay has emerged as a promising method to identify stem cells and determine drug efficacy in killing CSCs because it quantitatively analyzes the relative number $(\%)$ of stem-like cancer cells in the overall cancer cell population $[8,9]$. 
In lung cancer cells, ATP-binding cassette sub-family $\mathrm{G}$ member 2 (ABCG2), an ABC transporter member, is responsible for SP formation $[8,10]$. ABCG2 contributes to chemotherapeutic drug resistance in lung cancer treatment and appears to be a predictor of survival in patients with advanced non-small cell lung cancer [11]. SP cells sorted out from lung cancer cells also demonstrate a greater tumorigenic capacity than non-SP cells [5]. Consequently, determining the molecular mechanism that controls ABCG2 expression in lung cancer is very important for developing more effective therapy that can downregulate ABCG2 and lead to eradication of cancer stem cells.

The Hippo pathway was initially defined in Drosophila. Because mutations in components of this pathway lead to tissue and organ overgrowth, the Hippo pathway is considered as a tumor suppressor pathway. In mammals, the Hippo pathway consists of a conserved core kinase cascade that includes serine/threonine kinases MST1/2 (mammalian Ste2-like kinases 1/2) and LATS1/2 (large tumor suppressor kinase 1/2). In humans, when the Hippo pathway is activated MST1/2 phosphorylates and activates Lats1/2 kinase functions to inactivate Yesassociated protein 1 (YAP1) by directed phosphorylation on YAP1 Ser 127. Phosphorylated YAP1 is sequestered in the cytoplasm via binding to 14-3-3 and results in degradation. Conversely, dephosphorylated YAP1 localizes in the nucleus and acts mainly through TEAD family transcription factors to induce gene expressions that promote cell proliferation and organ growth. The other major effector of the Hippo pathway, called TAZ (transcriptional coactivator with PDZ binding motif), is regulated by LATS1/2 and acts with TEADs in a similar manner to that of YAP1 [12-14]. TEAD transcription factors mediate genome-wide YAP1 chromatin-binding [15]. The known consensus motif for TEAD is CATTCC [14]. YAP1 overexpression due to amplification of the YAP1 gene, loss of Hippo signaling by mutation, and/or down-regulation of core Hippo components have been found in many cancers [16]. YAP1 overexpression also contributes to self-renewal and tumorinitiation capacities in cancer stem cells $[17,18]$. YAP1 also reportedly contributes to promoting resistance to anticancer drugs in different cancers like ovarian cancer and hepatocellular carcinoma cells [19-22]. Verteporfin (trade name Visudyne) has been identified as a YAP1 inhibitor and can be readily used to study the effects of YAP1 [23, 24]. However, the relationship between YAP1 and ABCG2 and YAP1 regulation of cancer cell side population in lung cancer have never been reported.

In this study, we asked whether YAP1 regulates ABCG2 in lung cancer cells. To answer this question, we investigated whether ABCG2 is a direct downstream target of YAP1 and the potential therapeutic advantage of this transcriptional regulation if it was confirmed.

\section{RESULTS}

\section{YAP1 activity and ABCG2 $\mathrm{mRNA}$ and protein levels are higher in SP cells than in non-SP cells}

In order to analyze ABCG2 and YAP1 in SP cells, we first sought to determine whether SP cells were present in human NSCLC cell lines A549 and H460 and to sort out SP cells and non-side population (non-SP) cells for analysis. The SP cells were detected based on their ability to exclude Hoechst 33342 dye and appeared as a distinct tail at the bottom-left corner in the flow cytometry plots. When the cells were pretreated with the ABC transporter inhibitor verapamil, the tail disappeared or faded out. The position where the tail disappeared was used as a control to gate the area of SP cells. The A549 and H460 cell lines respectively contained $1.28 \%$ and $3.98 \%$ SP cells. After the cells were treated with verapamil, these percentages decreased to $0.019 \%$ in A549 cells and $0.119 \%$ in $\mathrm{H} 460$ cells (Figure 1A). Western blot analysis of protein in H460 SP and non-SP cells showed lower levels of LATS1, phosphate-LATS1 and phosphate-YAP1 (S127), but higher total YAP1 and ABCG2 levels in H460 SP cells than in non-SP cells (Figure 1B). Around 3-fold YAP/P-YAP ratio in SP cells of in non-SP cells indicated higher YAP1 activity present in SP cells (Figure 1C), as did the higher level of GTIIC reporter activity in H460 SP cells than in non-SP cells (Figure 1D). The SP and non-SP cells in both NSCLC cell lines were then analyzed using Q-RT-PCR. In both cell lines, mRNA levels of ABCG2, YAP1 and YAP1 downstream genes including BIRC5, CTGF and CYR61 were higher in SP cells than in non-SP cells except $C D 133$ and $A R E G$ (Figure $1 \mathrm{E}$ and $1 \mathrm{~F}$ ).

\section{Knockdown of YAP1 decreases ABCG2 expression, the percentage of $\mathrm{SP}$ cells and the number of spheres formed in A549 and $\mathrm{H} 460$ cells}

To investigate whether depletion of YAP1 influences ABCG2, we treated A549 and H460 cell lines with two different YAP1 siRNAs (siYAP1 \#1 and siYAP1 \#2). Both YAP1 siRNAs reduced YAP1 mRNA level and protein level significantly, as shown by Q-PCR and western blot analysis (Figure 2A-2D). Knockdown of YAP1 decreased ABCG2 mRNA and protein levels. Since the two YAP1 siRNAs had similar knockdown effects, we only chose siYAP1 \#2 for SP assay analysis and sphere formation analysis. SP analysis showed that knockdown of YAP1 reduced the percentage of SP cells from $1.92 \%$ to $0.735 \%$ in A549 cells and from $3.95 \%$ to $1.24 \%$ in $\mathrm{H} 460$ (Figure 2E to $2 \mathrm{H}$ ). Knockdown of YAP1 also significantly reduced the number of spheres in H460 and A549 (Figure 2I and 2J). 


\section{Overexpression of YAP1 increases ABCG2 expression and the percentage of SP cells in A549 and $H 460$ cells}

To verify that $\mathrm{ABCG} 2$ can be regulated by YAP1 expression, we analyzed ABCG2 protein level after forced over-expression of YAP1 gene in A549 and $\mathrm{H} 460$ by plasmid transfection. We found that YAP1 protein level was increased after YAP1 plasmid transfection, indicating that YAP1 plasmid transfection was successful and YAP1 was overexpressed. Along with the YAP1 overexpression, ABCG2 protein level was increased (Figure 3A). The mRNA level of ABCG2 was also increased in purified SP cells after YAP1 overexpression (Figure 3F and 3G). SP assay analysis of the cells transfected with YAP1 O/E plasmid and empty vector indicated that YAP1 overexpression upregulated the SP cell portion in A549 from $0.667 \%$ to $0.868 \%$ and upregulated the SP cell portion in $\mathrm{H} 460$ from $6.60 \%$ to $9.00 \%$ (Figure 3B to 3E).

\section{Overexpression of YAP1 does not increase ABCG2 expression and the percentage of SP cells in purified A549 and H460 non-SP cells}

To examine whether YAP1 can actively turn non-SP cells into SP cells, we purified non-SP cells from A549 and H460, over-expressed YAP1 through YAP1 plasmid transfection, and measured the change in the percentage of SP cells. YAP1 protein level was increased nearly 3-fold after transfection, which indicated YAP1 was successfully overexpressed (Figure 4A and 4B). However, ABCG2 protein level and the percentage of SP cells did not increase after overexpression of YAP1 in purified non-SP cells (Figure 4E to 4F). Since YAP1 activity was lower in H460 non-SP cells due to higher level of active LATS1, we wondered if the unchanged ABCG2 level and SP percentage were due to inactivation of YAP1 by phosphorylation on Ser 127 of YAP1. We examined the phosphate-YAP1 (S127) level and found an increase of P-YAP1 together with the increase of total YAP1.

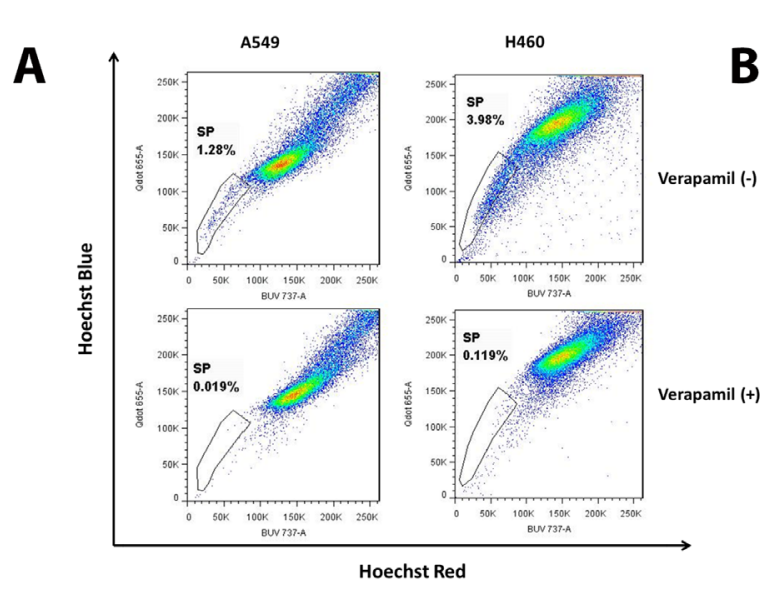

$\mathbf{E}$
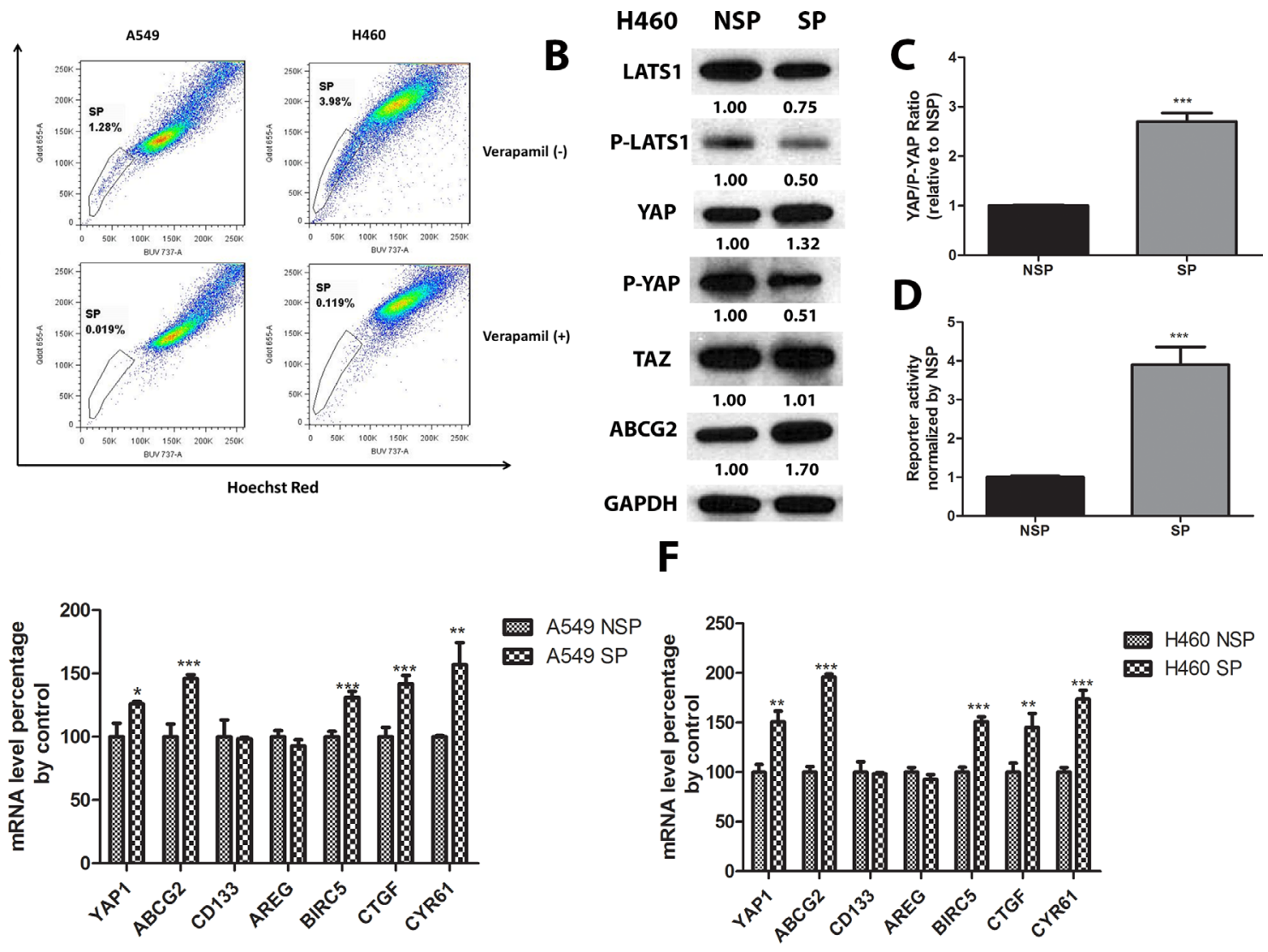

Figure 1: YAP1 activity and ABCG2 mRNA and protein levels are higher in SP cells than in non-SP cells. (A) Flow cytometry analysis of SP cells in A549 and H460 shows portion of SP cells in A549 and H460; (B) Western blot analysis of LATS1, P-LATS1 (Thr1079), YAP1, P-YAP1 (Ser127), TAZ, and ABCG2 protein level in H460 non-SP cells and SP cells. GAPDH was detected as a loading control. Band intensity was analyzed with ImageJ software and normalized with the intensity of GAPDH band. (C-D) Bar graph showing YAP/P-YAP ratio in purified SP and non-SP (NSP) of A549 and H460. (E-F) qPCR analysis of mRNA level of YAP1, ABCG2, CD133, AREG, BRIC5, CTGF, and CRY61 in non-SP cells and SP cells of H460 and A549. Data are representative of at least three independent experiments. Error bars indicate the standard deviation of triplicate qPCR data. ${ }^{*} P<0.05, * * P<0.005,{ }^{* * *} P<0.001$. 
Comparing the YAP1/P-YAP1 ratio, we found no difference between control and YAP1- overexpressed non-SP cells (Figure 4C and 4D). However, when we overexpressed YAP1 S127A, the YAP1 mutant that cannot be phosphorylated by LATS1/2 and is continuously active, the SP percentage of purified non-SP cells was increased (Supplementary Figure S1A-S1D). When we overexpressed YAP1 wild type in purified and cultured SP cells, the SP percentage also was increased (Supplementary Figure S2A-2D).
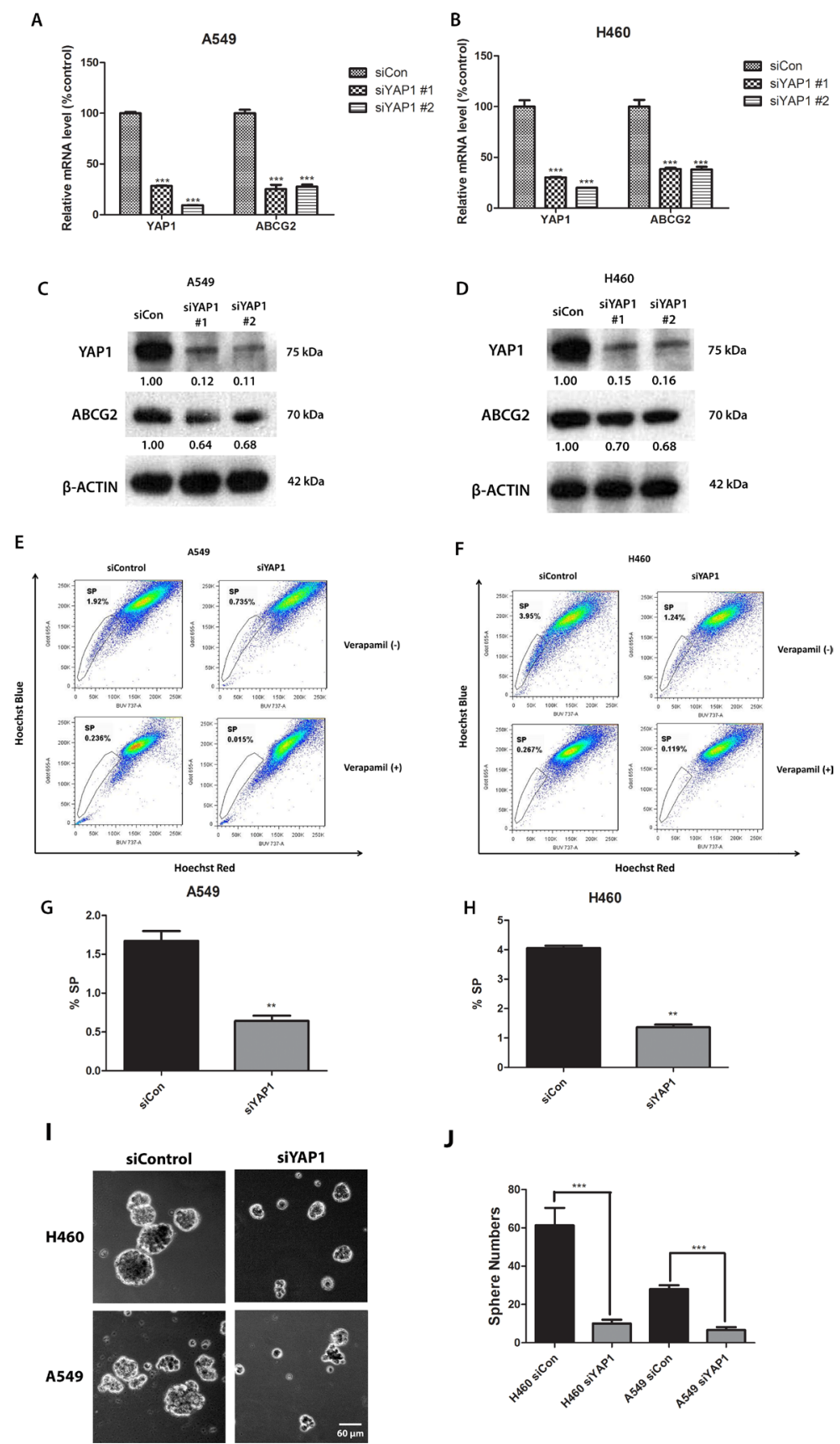

J

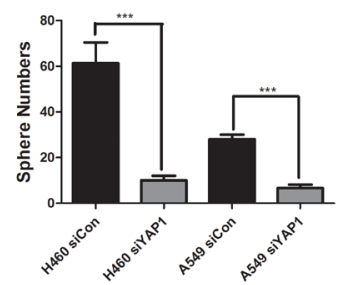

Figure 2: Knockdown of YAP1 decreases ABCG2 expression and the percentage of SP cells in NSCLC cell lines A549 and H460. (A-B) qPCR analysis of mRNA level of YAP1 and ABCG2 in H460 and A549 after YAP1 siRNA (siYAP1\#1 and siYAP1 \#2) treatment. (C-D) Western blot analysis of protein level of YAP1 and ABCG2 in H460 and A549 after YAP1 siRNA treatment. $\beta$-ACTIN was detected as a loading control. Band intensity was analyzed with ImageJ software and normalized with the intensity of $\beta$-ACTIN band. (E-F) Flow cytometry analysis of the SP cell portion in A549 and H460 after siYAP1 \#2 treatment. (G-H) Bar graph showing the percentage of SP cells in A549 and H460 after siYAP1 \#2 treatment. (I) Sphere formation analysis of H460 and A549 after control or YAP1 siRNA transfection. (J) Bar graph showing the number of spheres formed in H460 and A549 after control or YAP1 siRNA transfection. Data are representative of at least three independent experiments. Error bars indicate the standard deviation of triplicate qPCR data and SP assay data. $* * P<0.005$. 


\section{YAP1 regulates $A B C G 2$ at the transcriptional level through binding to the promoter of ABCG2}

Our earlier experiments indicated that ABCG2 expression is regulated by YAP1. YAP1 as a transcription coactivator, together with TEAD family proteins, regulates many genes, including CTGF [14]. We therefore wondered whether YAP1 regulates ABCG2 at the transcriptional level. We examined the ABCG2 promoter region (-1000 bp upstream of transcription starting site of $\mathrm{ABCG} 2$ ) and found one putative TEAD-binding site (CATTCC), which is
540 bp upstream of the ABCG2 transcription start site (Figure 5A). We used chromatin immunoprecipitations (ChIPs) to test our hypothesis. We found that in H460 cells, ChIP studies using a YAP1-specific antibody resulted in the precipitation of $\mathrm{ABCG} 2$ promoter region encompassing the putative TEAD binding site (Figure 5B). In the control ChIP assay using Rabbit IgG or without any antibody, we did not detect ABCG2 promoter-region binding. These findings confirmed the direct occupation of YAP1 to the promoter region of ABCG2. Performing ChIP on YAP1 siRNA transfected samples, we detected less ABCG2 promoter region
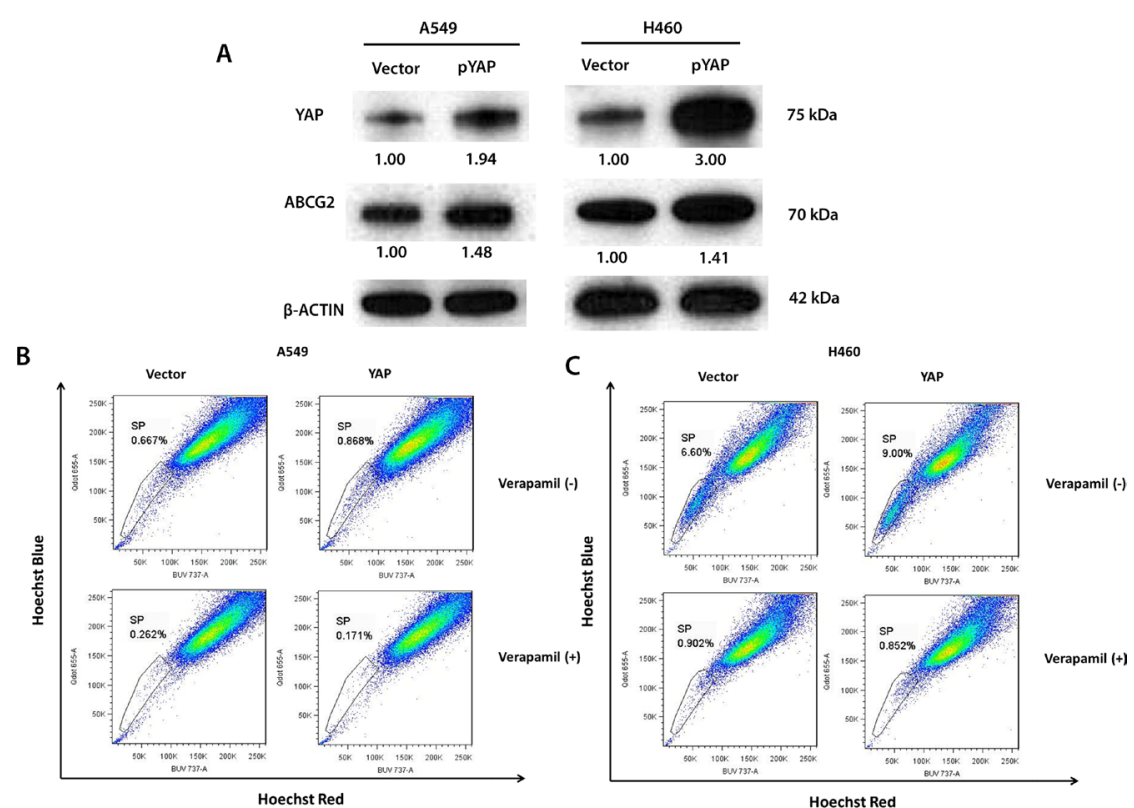

D

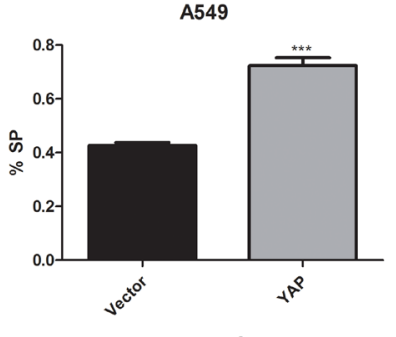

$E$
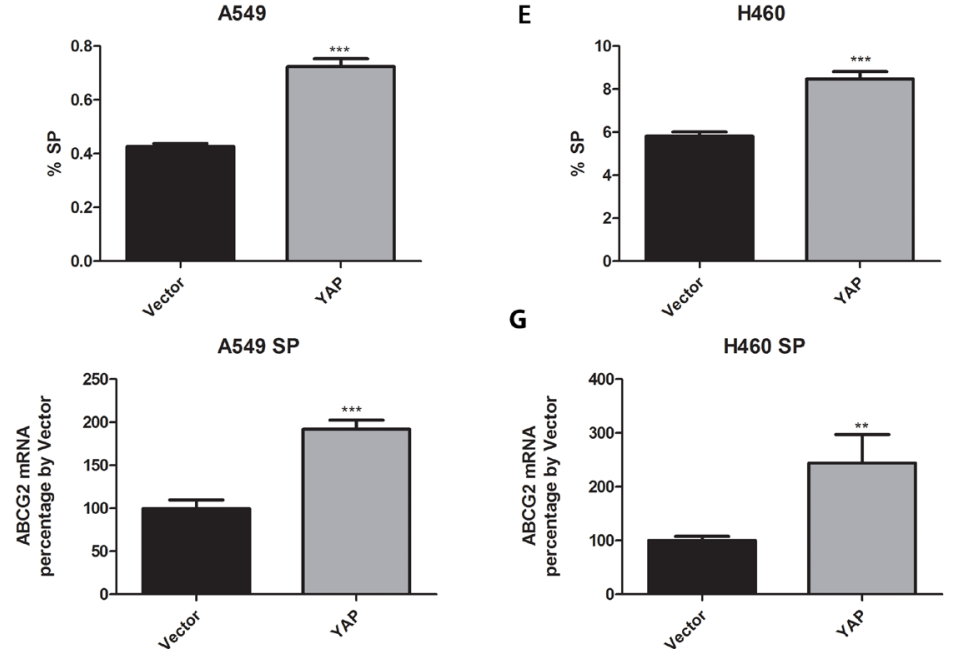

G

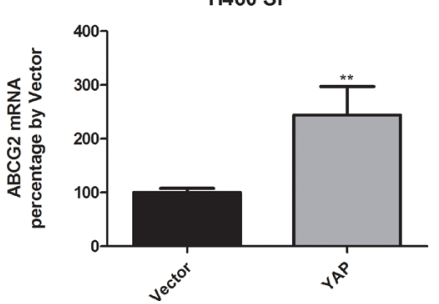

Figure 3: Knockdown of YAP1 decreases ABCG2 expression, the percentage of SP cells and the number of spheres formed in A549 and $\mathbf{H 4 6 0}$ cells. (A) Western blot analysis of protein level of YAP1 and ABCG2 in H460 and A549 cells after YAP1 plasmid transfection. $\beta$-ACTIN was detected as a loading control. Band intensity was analyzed with ImageJ software and normalized with the intensity of $\beta$-ACTIN band. (B-C) Flow cytometry analysis of the percentage of SPs in A549 and H460 cells after YAP1 plasmid transfection. (D-E) Bar graph showing the percentage of SP cells in A549 and H460 cells after YAP1 plasmid transfection. (F-G) qPCR analysis of mRNA level of ABCG2 in purified SP cells of $\mathrm{H} 460$ and A549 after control or YAP1 plasmid transfection. Data are representative of at least three independent experiments. Error bars indicate standard deviation of triplicate SP assay data. ${ }^{* *} P<0.005, * * * P<0.001$. 
precipitation in $\mathrm{H} 460$ cells (Figure $5 \mathrm{~B}$ and $5 \mathrm{C}$ ). The results of our Q-RT-PCR experiments also confirmed that YAP1 siRNA decreased YAP1 transcriptional regulation activity on ABCG2 (Figure 4D). We also found that TEAD1 bound to the same promoter region of ABCG2 as YAP1 (Supplementary Figure S3).
The YAP1-TEAD complex inhibitor verteporfin reduces ABCG2 expression, SP cell percentage and sphere formation in A549 and $\mathrm{H} 460$ cells

Verteporfin is a YAP1-TEAD complex inhibitor that can inhibit the transcriptional activity of the YAP1-TEAD
A

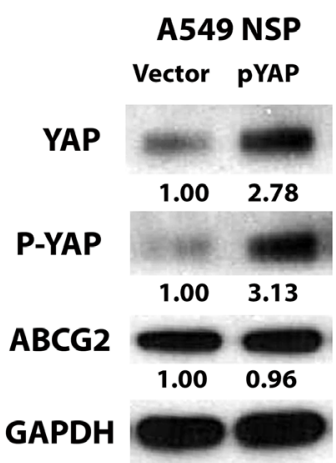

C

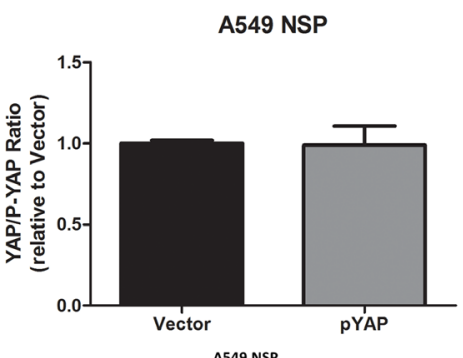

E
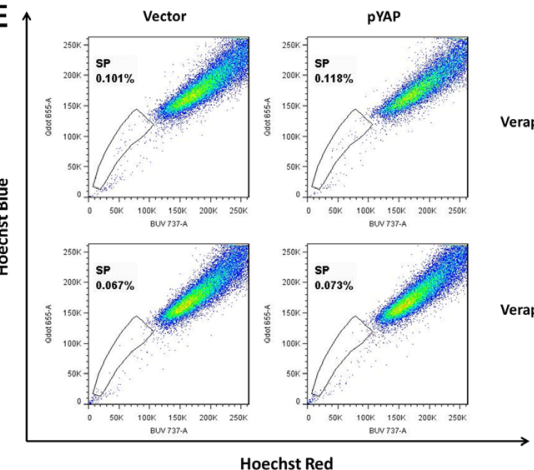

G

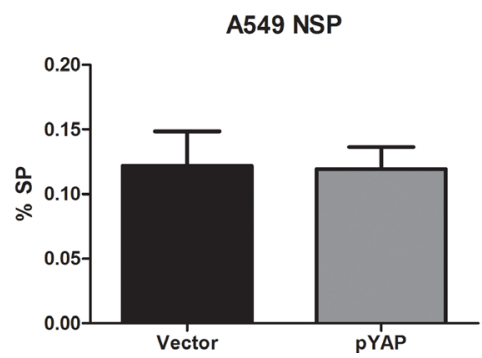

B

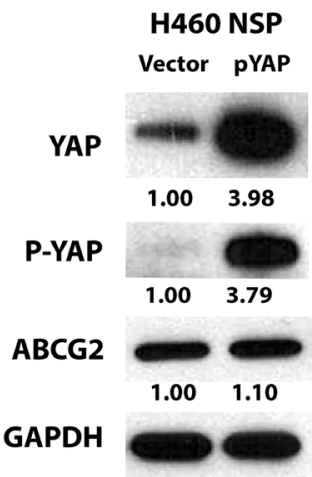

D

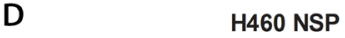

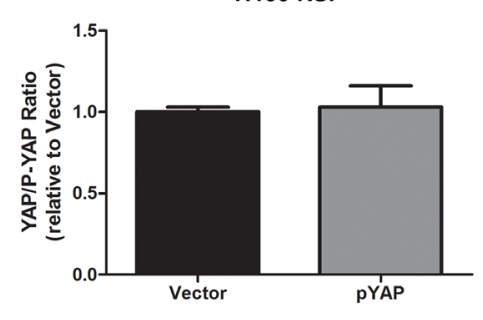

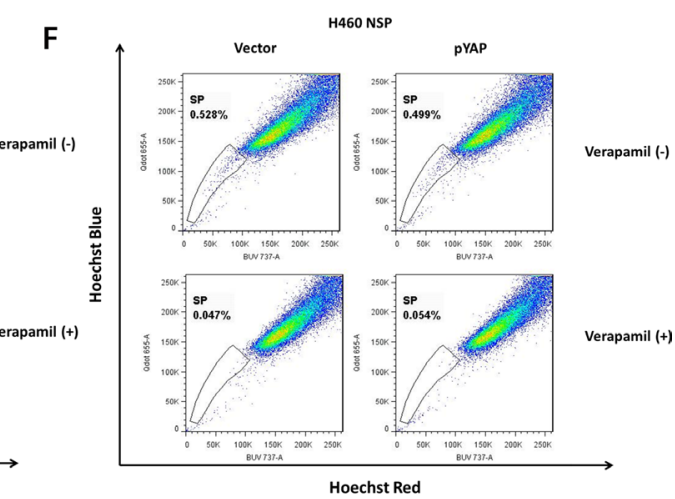

$\mathrm{H}$

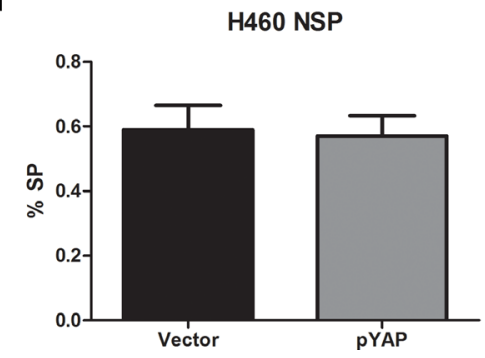

Figure 4: Overexpression of YAP1 does not increase ABCG2 expression and the percentage of SP cells in purified A549 and H460 non-SP cells. (A-B) Western blot analysis of protein levels of YAP1, P-YAP1 (Ser127) and ABCG2 in A549 and H460 cells after YAP1 plasmid transfection. GAPDH was detected as a loading control. Band intensity was analyzed with ImageJ software and normalized with the intensity of GAPDH band. (C-D) Bar graph showing YAP/P-YAP ratio in purified non-SP (NSP) of A549 and H460 after YAP1 plasmid transfection. (E-F) Flow cytometry analysis of the percentage of SPs in A549 and H460 cells after YAP1 plasmid transfection. (G-H) Bar graph showing the percentage of SP cells in A549 and H460 cells after YAP1 plasmid transfection. Data are representative of at least three independent experiments. 
complex by preventing YAP1 and TEAD interaction [23-25]. To investigate whether inhibiting YAP1-TEAD activity affects ABCG2 in A549 and H460 cell lines, we treated the cells with serial concentration dilutions of verteporfin in 96 wells to measure the $\mathrm{IC}_{50}$ (the drug concentration that kills $50 \%$ of cells) for A549 and H460 cells and determined the concentration for the SP assay. The $\mathrm{IC}_{50}$ of vertepofin was $5.59 \pm 1.50 \mu \mathrm{M}$ for A549 and $5.01 \pm 1.24 \mu \mathrm{M}$ for H460. The lowest concentration of verteporfin tested whereby cells started to show a response was $1 \mu \mathrm{M}$. After cells were treated with $1 \mu \mathrm{M}$ verteporfin, cell viability was $97 \%$ for A549 cells and 93\% for H460 cells. The cell viabilities for the same cell lines treated with vehicle DMSO were both $100 \%$. Therefore, we chose $1 \mu \mathrm{M}$ as the verteporfin concentration for western blot analysis and the SP assay. The results of the western blot analysis showed that verteporfin decreased the YAP1 protein level (Figure 6A). The ABCG2 protein level also decreased when YAP1 was downregulated after verteporfin treatment (Figure 6A). We used $\beta$-actin as the protein gel loading control in the western blot analysis. SP assay analysis of the cells treated with verteporfin or vehicle DMSO indicated that verteporfin reduced the percentage of SP cells in A549 from $0.640 \%$ to $0.012 \%$ and reduced the percentage of SP cells in $\mathrm{H} 460$ from $2.06 \%$ to $0.007 \%$ (Figure $6 \mathrm{~B}$ to $6 \mathrm{E}$ ). Verteporfin also significantly reduced the sphere formation of H460 and A549 (Figure 6F to $6 \mathrm{H}$ ).

\section{Verteporfin potentiates the cytotoxicity of doxorubicin}

ABCG2 is involved in multidrug resistance including to doxorubicin [26]. Since verteporfin can inhibit ABCG2 transcription, we asked whether verteporfin could help doxorubicin inhibit tumor cell growth. We measured doxorubicin $\mathrm{IC}_{50}$ in A549 and H460 cells (Figure 7A and $7 \mathrm{~B})$. The $\mathrm{IC}_{50}$ of doxorubicin was $0.496 \pm 0.088 \mu \mathrm{M}$ for A549 cells and $0.226 \pm 0.045 \mu \mathrm{M}$ for $\mathrm{H} 460$ cells. When the cells were treated with doxorubicin alone or together with of various concentrations of verteporfin for 72 hours, we found that the combination of doxorubicin and verteporfin yielded stronger cytotoxic effects than either drug alone (Figure 7C and 7D). The isobolograms of $\mathrm{IC}_{50}$ were used to measure the combination index (CI) of two drugs[27] (Figure 7E and 7F). The $\mathrm{IC}_{50}$ isoboles lay to the left of the additive isoboles, which indicated synergistic action $(\mathrm{CI}<1)$, which in turn indicated that verteporfin significantly potentiated the cytotoxicity of doxorubicin in A549 and H460 cells. We also examined the effect of siYAP1 on the cytotoxicity of doxorubicin in A549 and H460 cells. Transfection of siYAP1 alone did

A
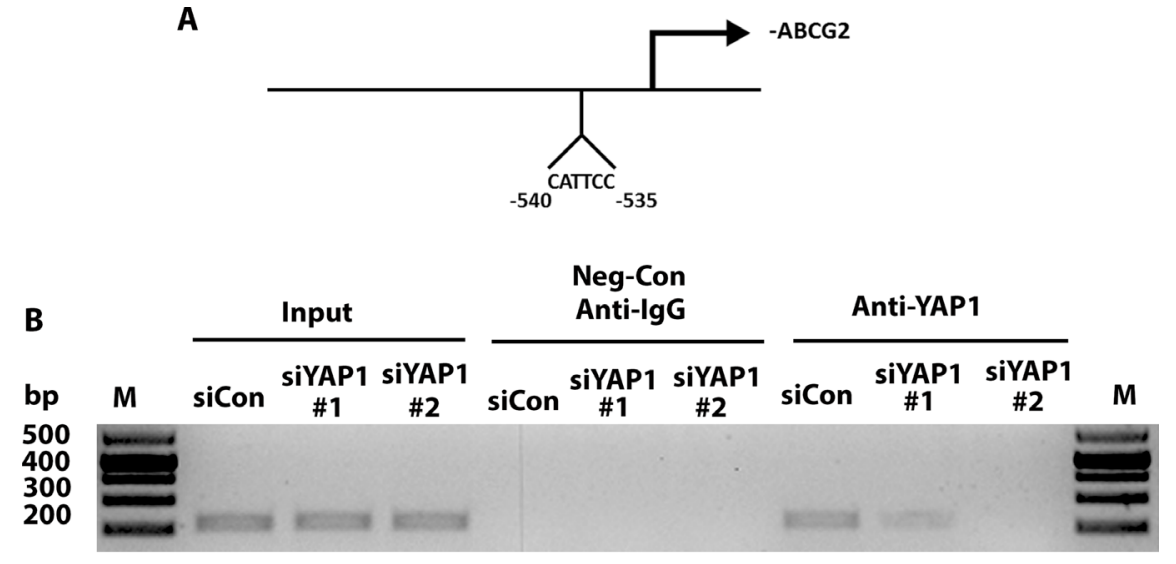

C

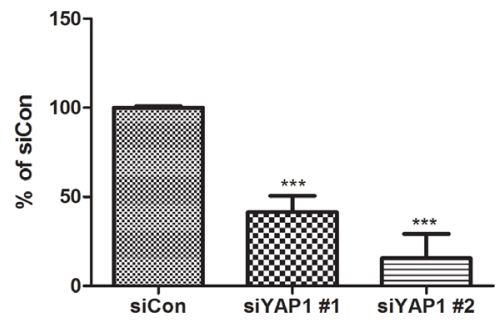

D

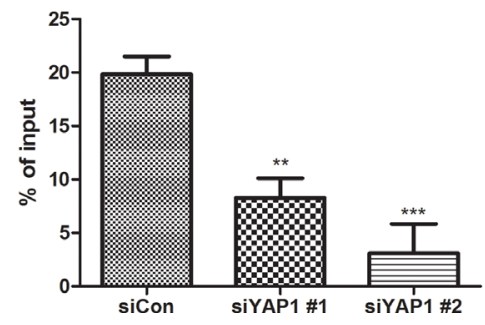

Figure 5: YAP1 regulates ABCG2 at the transcriptional level through binding to the promoter of ABCG2. (A) Schematic of the ABCG2 promoter region. Sequence analysis revealed a putative YAP1-TEAD co-binding site between -535 to -540 nucleotides upstream of the transcription start site. (B) ChIP assays were performed with H460 cells transfected with control siRNA (siCon) and two YAP1 siRNAs. (C) Bar graph showing band intensity of gel band of RT-PCR products. (C-D) qPCR analysis of ChIP assay product from H460 cells transfected with control siRNA (siCon) and two YAP1 siRNAs. Data are representative of at least three independent experiments. Error bars indicate the standard deviation of triplicate ChIP and qPCR data. $* * P<0.005, * * * P<0.001$. 
not significantly reduce cell viability (Figure $7 \mathrm{G}$ and $7 \mathrm{H}$ ) in either cell line. However, siYAP1-transfected cells were more sensitive to doxorubicin at different concentrations.
The enhancement of doxorubicin cytotoxicity by siYAP1 and $1 \mu \mathrm{M}$ verteporfin was similar (Figure $7 \mathrm{G}$ and $7 \mathrm{H}$ ). The $\mathrm{IC}_{50}$ of doxorubicin with $1 \mu \mathrm{M}$ of vertoporfin was
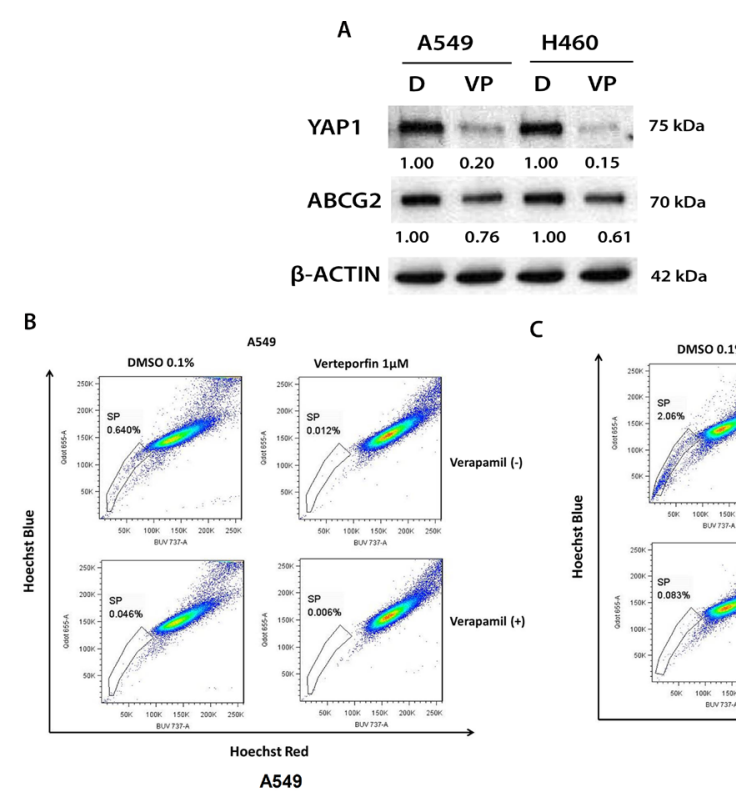

C

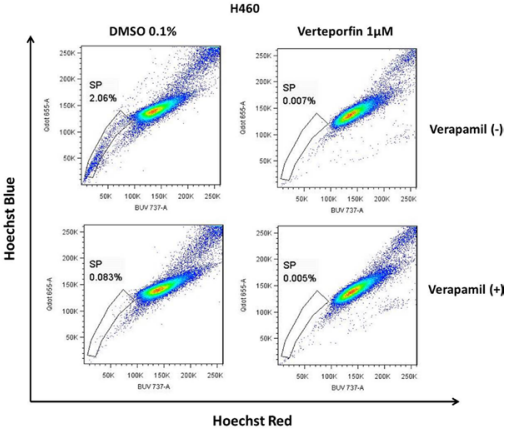

D

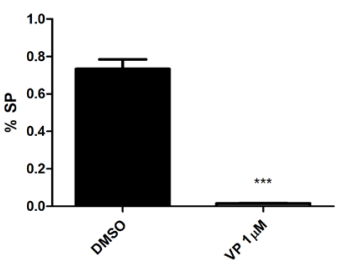

E
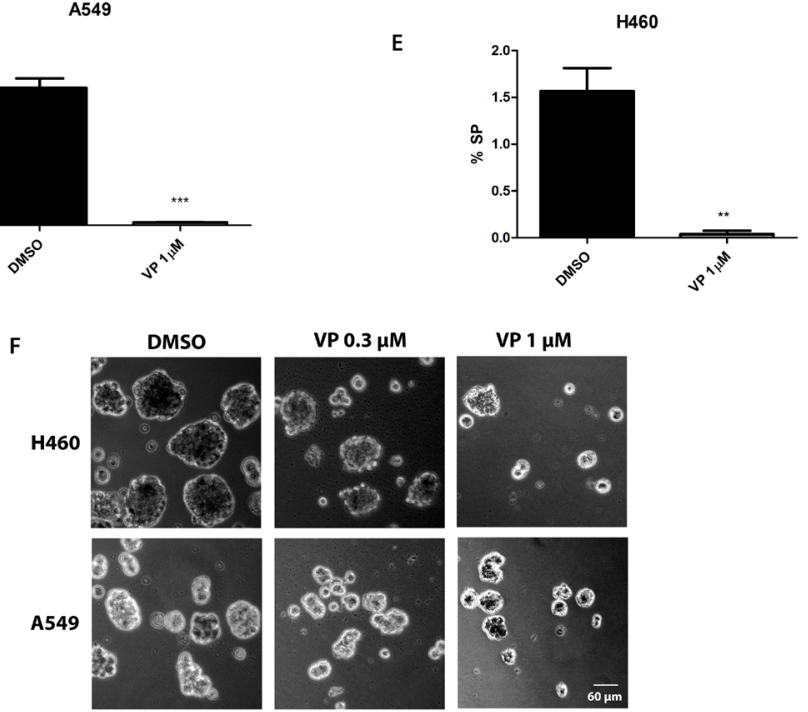

$\mathbf{G}$

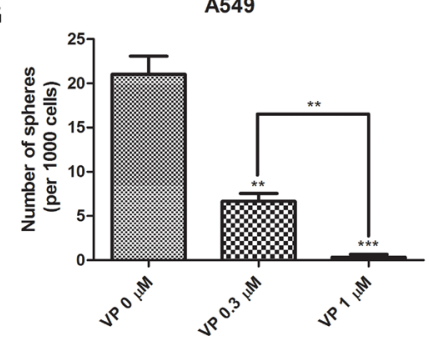

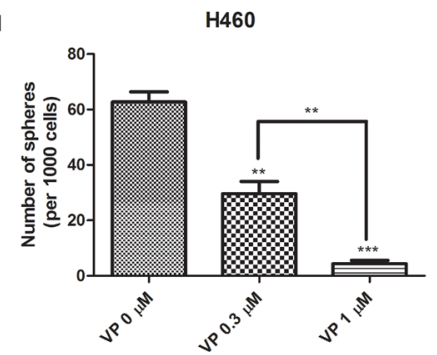

Figure 6: The YAP1-TEAD complex inhibitor verteporfin (VP) reduces ABCG2 expression, the percentage of SP cells and sphere formation in A549 and $\mathrm{H460}$ cell lines and potentiates the cytotoxicity of doxorubicin (DOX). (A) Western blot analysis of protein level of YAP1 and ABCG2 in H460 and A549 cells after $1 \mu \mathrm{M}$ verteporfin treatment. $\beta$-ACTIN was detected as a loading control. Band intensity was analyzed with ImageJ software and normalized with the intensity of $\beta$-ACTIN band. (B-C) Flow cytometry analysis of SP cell portion in A549 and H460 cells after $1 \mu \mathrm{M}$ verteporfin. (D-E) Bar graph showing SP cell portion in A549 and H460 cells after $1 \mu \mathrm{M}$ verteporfin. (F) Sphere formation analysis of H460 and A549 cells after 0.1\% DMSO, $0.3 \mu \mathrm{M}$ verteporfin or $1 \mu \mathrm{M}$ verteporfin . $(\mathbf{G}-\mathbf{H})$ Bar graph showing the number of spheres formed in A549 and H460 cells after 0.1\% DMSO, $0.3 \mu \mathrm{M}$ verteporfin or $1 \mu \mathrm{M}$ verteporfin. Data are representative of at least three independent experiments. 
slightly higher than that of doxorubicin with siYAP1 (Supplementary Table S1A). The $\mathrm{IC}_{50}$ of doxorubicin was lower with $2 \mu \mathrm{M}$ of verteporfin than with siYAP1 (Supplementary Table S1A). We also compared the sensitivity of SP and non-SP cells to doxorubicin with and without $1 \mu \mathrm{M}$ verteporfin (Supplementary Table S1B). The higher $\mathrm{IC}_{50}$ of doxorubicin in SP cells than in nonSP cells both in A549 and H460 cell lines indicated SP cells were more resistant to doxorubicin toxicity. Addition of $1 \mu \mathrm{M}$ verteporfin with doxorubicin reduced the $\mathrm{IC}_{50}$ of doxorubicin in SP cells and in non-SP cells.

\section{DISCUSSION}

The Hippo pathway consisting of the tumorsuppressing core-kinase cascade (MST and LATS) and oncogenic downstream effector YAP1/TAZ participates in tissue homeostasis, organ size control, and tissue repair and
A

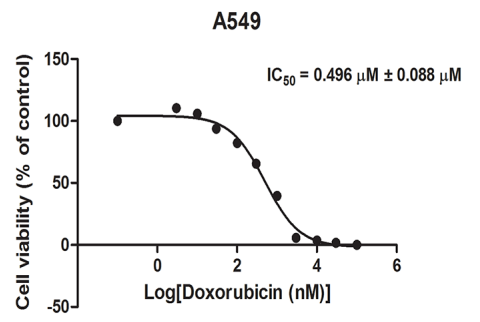

C

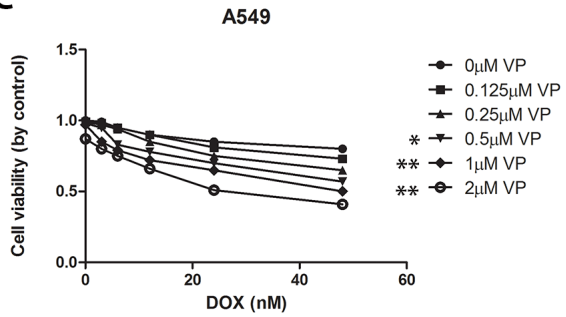

E

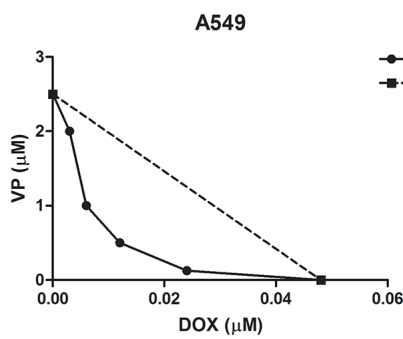

G

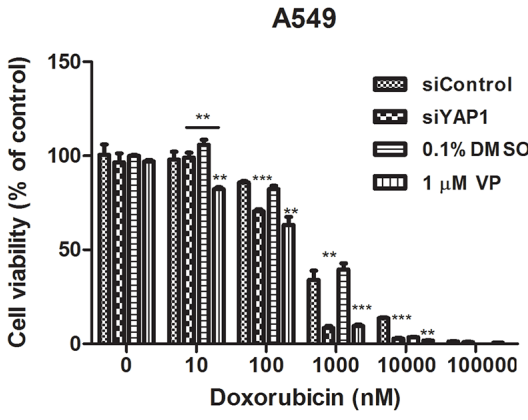

B

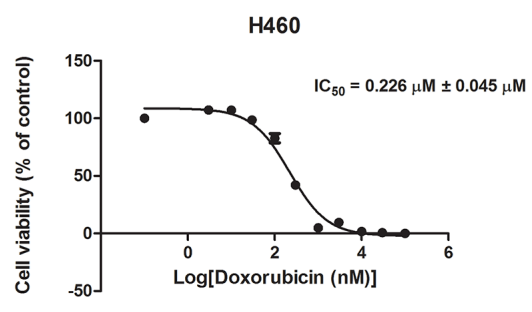

D

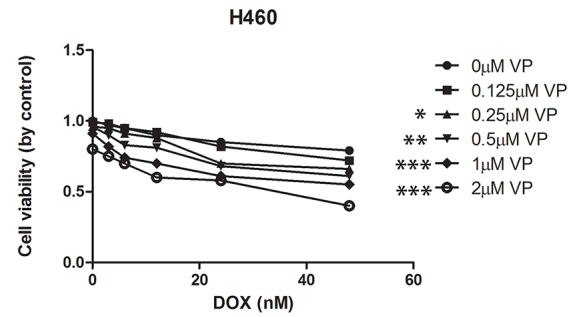

F

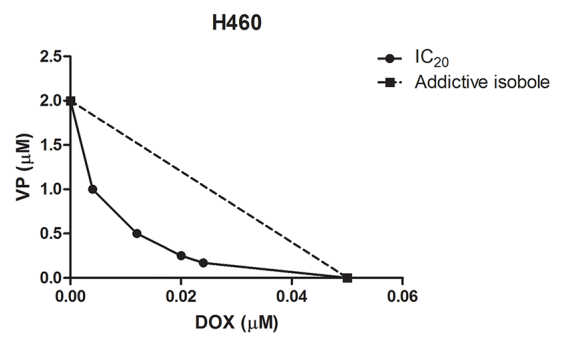

H $\quad \mathrm{H460}$

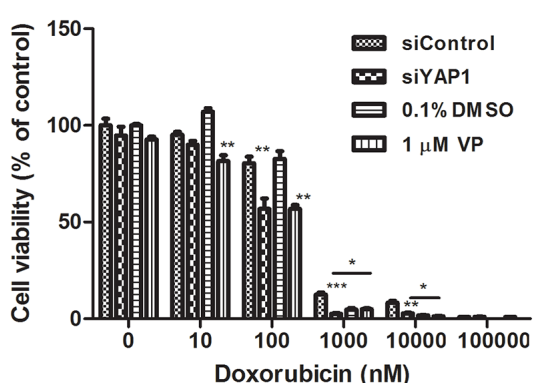

Figure 7:Cell viability analysis of A549 and $\mathrm{H460}$ cells treated with increasing concentrations of doxorubicin combined with different concentrations of verteporfin or with siYAP1 treatment. (A-B) Cell viability analysis of A549 and H460 cells treated with increasing concentrations of doxorubicin. Dose-dependent curve and $\mathrm{IC}_{50}$ were analyzed with Prism software. $\mathrm{IC}_{50} \mathrm{~S}$ were displayed on the figures. (C-D) A549 and H460 cells were treated with various combinations of verteporfin and doxorubicin for 72 hours. Cell viability was determined by Titer-Glo assay. Two way ANOVA analysis was performed between the VP combination treatment group and the control group without VP addition. (E-F) Synergism of proliferation inhibition of A59 and H460 cells was determined by isobologram analysis. (G-H) Cell viability of A549 and H460 with increasing concentrations of doxorubicin combined with siYAP1 or 1 $\mu \mathrm{M}$ verteporfin. Data are representative of at least three independent experiments. $* P<0.05, * * P<0.005, * * * P<0.001$. 
regeneration by regulating tissue-specific stem cells [18]. Dysregulation of the Hippo pathway leading to abnormal activity of YAP1/TAZ (e.g., a high protein level of YAP1/ TAZ and/or low phosphorylation level by LATS) has been associated with cancer development. Moreover, compelling evidence supports a role of YAP1/TAZ in cancer stem cells. Our study provides several lines of evidence for an expanded role for YAP1 in lung SP cells or cancer stemlike cells. First, YAP1 is overexpressed in purified H460 SP cells compared to non-SP cells. Further contributing to YAP1 activation, phosphorylation of S127 in YAP1 is also decreased in SP cells, indicating a hyper-activation status of YAP in SP cells. Second, ectopic expression of YAP1 increased the percentage of SP cells in both A549 and H460. Conversely, knockdown of YAP1 by siRNA or reducing YAP1/TEAD transcriptional activity by the YAP1 inhibitor verteporfin decreased the percentage of SP cells and cell self-renewal activity to form spheres in A549 and H460 cells. Third, overexpression of YAP1 increased the percentage of SP cells in purified H460 SP cells. However, WT YAP1 overexpression cannot convert purified non-SP cells into SP cells because the percentage of SP cells was similar for control and YAP1 O/E cells. In contrast, overexpression of YAP-S127A, which lacks the phosphorylation site required for inactivation by the Hippo pathway, can convert NSP cells to SP cells and increase the percentage of SP cells in purified $\mathrm{H} 460$ nonSP cells. This is consistent with our finding that protein and phosphorylation levels of LATS1 were lower in nonSP cells than in SP cells. The upper signal contributing to this difference is unknown. It may be regulated by a canonical Hippo pathway like MST1/2 or NF2 [28], or by Rho-GTPase independent of the Hippo pathway [29]. Interestingly, TAZ expression did not differ between $\mathrm{H} 460$ $\mathrm{SP}$ and non-SP cells. This is different from the breast cancer scenario. In breast cancer stem cells, TAZ, not YAP1, has been shown to be a key regulator of breast cancer stem cells. Collectively, our findings suggest an important role of the Hippo pathway and YAP1 in lung cancer stem-like cells.

We observed spontaneous conversion of non-SP-to-SP and SP-to-non-SP (Supplementary Figure S4). The conversion of non-SP-to-SP under our normal lung cancer cell culture conditions is slower than the conversion of SP-to-non-SP. But both the purified SP and non-SP cells reached a steady level resembling that of unsorted cultures after limited culture days and limited passages. Although the 4-way purity setting we used in a FACS-ARIA II cytometer is supposed to only sort drops free of contaminating particles, we cannot rule out possible cross-contamination between SP and nonSP fractions during cell purification. The reversibility of SP and non-SP was also found in embryonic stem cell cultures [30]. Despite use of a single cell purification method, there was still a conversion between these two fractions. Studies using other stem cell markers to purify stem cells also found that normal and neoplastic non-stem cells can spontaneously convert to a stem-like state [31]. The mechanism underlying the reversibility of SP and non-SP is currently unknown.

SP cells in human cancer cells show stem-like properties, including high tumorigenic activity and chemoresistance $[8,9]$. ABCG2 is the major contributor of the SP cell properties of lung cancer cells $[5,6,8]$. It is partially responsible for multi-drug resistance to chemotherapeutic treatment and its overexpression is linked to adverse prognosis in common forms of cancer $[3,4,11,26$, 32-36]. We found co-localization of ABCG2 and the Hippo pathway effector YAP1 in lung carcinoma SP cells. Our ChIP data indicated that YAP1 directly regulated ABCG2 expression at the transcriptional level in H460 lung cancer cells. The change in ABCG2 protein level was concurrent with YAP knockdown or overexpression, which also suggested a positive regulation of ABCG2 by YAP1. Hence addition of a YAP inhibitor to an ABCG2 substrate like doxorubicin [37] is highly likely to cause a synergetic rather than an additive effect on cancer cell viability. Consistently, we found that co-treatment with the chemotherapeutic agent doxorubicin and the YAP1-TEAD inhibitor verteporfin, or knockdown of YAP expression with siYAP1, improved the efficacy of doxorubicin in lung carcinoma cells in a synergistic manner. This synergistic effect was also present in purified SP and non-SP lung cancer cells (Supplementary Table S1B).

Accumulating evidence suggests that YAP1 plays a role in promoting drug resistance, including chemotherapy and target therapy [19-22, 38, 39]. The mechanism of YAP1-promoted resistance includes activation of the receptor tyrosine kinase $A X L$, the apoptosis inhibitor Survivin (BIRC5) genes, and autophagy depending on different drugs in different cancers. Our finding expands what is known about YAP1-promoted drug resistance through regulating a well-known $\mathrm{ABC}$-transporter, $\mathrm{ABCG} 2$, in lung cancer. To the best of our knowledge, ours is the first study to report that YAP1 directly transcriptionally regulates $\mathrm{ABCG} 2$, a major multidrug transporter implicated in lung cancer, and that deactivation of YAP1 efficiently eliminates SP cells in lung cancer cells. We cannot rule out that crosstalk or a combination of different mechanisms underlies the synergistic effect of verteporfin or siYAP with doxorobucin treatment in lung cancer cells. A recent study also linked YAP1 overexpression with other $\mathrm{ABC}$-transporters, including $\mathrm{ABCC} 1$ and $\mathrm{ABCB} 1$, in ovarian initiated cells [40]. However, ABCG2 was not reported as a downstream effector of YAP1 in that study.

Because YAP1 holds potential for cancer therapy, the mechanism by which the YAP1 inhibitor verteporfin exerts its action has also been studied. Verteporfin initially was proposed as a YAP1-TEAD complex inhibitor that prevented YAP1-TEAD interaction [24]. Subsequently, more evidence, including our current study, indicated 
verteporfin can also decrease YAP1 protein level [39]. The mechanism for YAP reduction by verteporfin is through upregulation of 14-3-3 $\sigma$, which sequesters YAP1 in the cytoplasm and leads to YAP1 degradation [41]. However, verteporfin can act as an autophagosome inhibitor by promoting oligomerization of p62 and inhibit colon cancer progression independently of YAP1 $[25,42]$. Hence, more specific inhibitors for YAP1/TEAD are needed for future study and clinical application.

ABCG2 has been shown to be transcriptionally regulated by Gli1, E2F1 and Nrf2 under different conditions in different cell types [43-45]. Further study is needed to determine whether the regulation of ABCG2 by these proteins and YAP1 involves cross-talk or is independent, and which protein is the major regulator under different scenarios. YAP1 is known to play important roles in organ size control and tumorigenesis [12-14]. Our study adds an important new function for YAP1 that may be relevant to cancer stem cells, drug resistance and cancer therapy. Future studies should focus on whether YAP1-ABCG2 regulation is active in a variety of tumor types and whether this affects the outcomes of clinical drugs for each disease.

\section{MATERIALS AND METHODS}

\section{Cell culture}

A549 and H460 established human lung cancer cell lines (originally purchased from The American Type Culture Collection, Manassas, VA) were cultivated in RPMI-1640 medium supplemented with 10\% fetal bovine serum, 100 units $/ \mathrm{ml}$ penicillin and $100 \mu \mathrm{g} / \mathrm{ml}$ streptomycin. Culture flasks were kept at $37^{\circ} \mathrm{C}$ and $5 \%$ $\mathrm{CO}_{2}$ in a humidified atmosphere.

\section{Reagents}

Verteporfin and ( \pm )-verapamil hydrochloride were purchased from Sigma (St. Louis, MO, USA). Hoechst 33342 and propidium iodide were purchased from Invitrogen Corporation (Waltham, MA, USA). Doxorubicin hydrochloride was purchased from Fisher Scientific (Pittsburgh, KS, USA). The SMARTPool siRNAs targeting YAP1 and control siRNA were purchased from Thermo Scientific Dharmacon (Pittsburgh, PA, USA). The YAP and YAP S127A plasmid DNA were purchased from Addgene (Cambridge, MA, USA).

\section{Cell viability assay}

The cytotoxicity of verteporfin was evaluated with the CellTiter-Glo luminescent cell viability assay (Promega, Madison, WI). Cells were seeded in 96-well plates at 5000 cells/well density, incubated for 24 hours for attachment and treated with different concentrations of verteporfin, or with doxorubicin with or without verteporfin for another 72 hours. Then $100 \mu \mathrm{l}$ of the CellTiter-Glo reagent was added into each well for a 10 -minute incubation. The plate was read by a GloMax 96 microplate luminometer (Promega, Madison, WI) to monitor the luminescence signal generated by the luciferase-catalyzed reaction of luciferin and ATP.

\section{Side population assay and sorting}

Cells were treated with $0.1 \%$ DMSO (control) or $1 \mu \mathrm{M}$ verteporfin for 72 hours, trypsinized and resuspended in DMEM with $2 \%(\mathrm{v} / \mathrm{v})$ FBS medium at $1 \times 10^{6}$ cells/ml concentration, and incubated with $5 \mu \mathrm{g} / \mathrm{ml}$ Hoechst 33343 dye in the presence or absence of $100 \mu \mathrm{M}$ verapamil at $37^{\circ} \mathrm{C}$ for $60 \mathrm{~min}$. Tubes were gently inverted every $20 \mathrm{~min}$ and then centrifuged at $400 \times \mathrm{g}$ for $5 \mathrm{~min}$ at $4^{\circ} \mathrm{C}$. The pellets were resuspended in cold PBS containing $2 \mu \mathrm{g} / \mathrm{ml}$ propidium iodide and analyzed on a BD FACS Aria II cell sorter. Emission was collected through a $610-\mathrm{nm}$ long pass dichronic mirror to a $620-\mathrm{nm}$ long pass filter for the Hoechst red (x-axis) collection and a 424/44-nm band pass filter for the Hoechst blue (y-axis) collection. The side population was identified as a group of cells able to exclude the Hoechst dyes, a characteristic inhibited with verapamil. In each experiment, the SP gate was set on the basis of the $100 \mu \mathrm{M}$ verapamil control sample. The detailed step-by-step gating strategy to exclude debris and dead cells was followed [46]. Side population cells and non-SP cells were sorted into $5 \mathrm{ml}$ tubes. The sorting mode was set as Device: 2 tubes; Precision: 4-Way Purity; Target Events: Continuous.

\section{Sphere formation assay}

Cells were treated with $0.1 \%$ DMSO (control) or with 0.3 or $1 \mu \mathrm{M}$ verteporfin for 72 hours. Cells were then trypsinized and resuspended in serum-free $\alpha$-MEM supplemented with $20 \mathrm{ng} / \mathrm{ml}$ EGF, $10 \mathrm{ng} / \mathrm{ml} \mathrm{bEGF}$, and B27 (BD Biosciences, San Jose, CA) and $1 \times 10^{3}$ cells / well were seeded into 24-well ultra-low adhesion plates (Corning, Corning, New York). The cells were cultured for 5 days, and then spheres with diameter larger than $50 \mu \mathrm{m}$ in 9 fields were counted.

\section{Western blot analysis}

Side population and non-SP H460 Cells were sorted and collected from the cell sorter, pelleted down, washed with PBS and lysed with M-PER Mammalian Protein Extraction Reagent (Thermo Scientific) supplied with Complete Protease Inhibitor Cocktails (Roche). Protein concentration was measured with a colorimetric BCA Protein Assay Kit (Pierce). $10 \mu \mathrm{g}$ protein were separated on $4-20 \%$ precast polyacrylamide gels (BioRad) and transferred onto PVDF membranes. Membranes were 
blocked with 5\% non-fat milk in Tris Buffered SalineTween (TBS-T) at room temperature for $1 \mathrm{hr}$ and incubated with ABCG2 antibody (Santa Cruz Biotech, Santa Cruz, CA, USA) at 1:1000 dilution or with $\beta$-actin at 1:40000 dilution overnight followed by HRP-conjugated secondary antibodies. Immunoreactive proteins were visualized using SuperSignal West Femto Chemiluminescent Substrate (Thermo Scientific).

\section{Quantitative real-time-PCR}

Total RNA was extracted from SP and non-SP cells using the RNeasy Mini Kit (Qiagen, Valencia, CA). The cDNA was transcribed using the iScript cDNA Synthesis Kit (Bio-Rad, Hercules, CA). The cDNA was used as a template for real-time PCR using the Applied Biosystems 7000 sequence detection system (Applied Biosystems, Foster City, CA). Expression of ABCG2 and endogenous control gene $\beta$-glucuronidase (GUSB) were detected using the commercially available primer and probe (Applied Biosystems) and analyzed using Relative Quantification Software (Applied Biosystems).

\section{ChIP assay}

The ChIP assay was conducted using the Chromatin Immunoprecipitation (ChIP) Assay Kit (Millipore Corporation). Polyclonal antibodies for YAP (Cell Signaling Technology) and control rabbit antibody for IgG (Cell Signaling Technology) were used for ChIP. Primers used for RT-PCR to amplify the ABCG2 gene were 5'-GGTACTGATCAGCCCAATGA-3' and 5'TGCGACCCGGCTGAAAGCGC-3', resulting in a product size of $202 \mathrm{bp}$. Primers used for quantitative PCR to detect ABCG2 were 5'-GGTACTGATCAGCCCAATG A-3' and 5'-CAGGGACAAGCCAAACACT-3'. This Q-PCR analysis was performed using Qiagen SYBR Green/Rox qPCR Master Mix (Qiagen) and Applied Biosystems 7000 sequence detection system (Applied Biosystems, Foster City, CA).

\section{Statistical analysis}

Data are presented as mean \pm standard deviation (SD). Statistical significance of differences between different groups was determined by Student's $t$-test. The level of statistical significance was set at $\leq 0.05$. The combination index (CI) was calculated by CompuSyn software using the Chou and Talalay method [47]. CI $<1$, $=1$ and $>1$ represent synergy, additivity, and antagonism, respectively.

\section{ACKNOWLEDGMENT}

We thank Pamela Derish in the UCSF Department of Surgery for editorial assistance with the manuscript.

\section{CONFILICTS OF INTEREST}

The authors declare no competing financial interests.

\section{GRANT SUPPORT}

This study was supported by the National Institutes of Health (NIH; Grant No. R01 CA140654, to LY). We are grateful for support from the Kazan McClain Partners' Foundation; the Estate of Robert Griffiths; the Jeffrey and Karen Peterson Family Foundation; Paul and Michelle Zygielbaum; the Estate of Norman Mancini; and the Barbara Isackson Lung Cancer Research Fund.

\section{REFERENCES}

1. Pattabiraman DR, Weinberg RA. Tackling the cancer stem cells - what challenges do they pose? Nat Rev Drug Discov. 2014; 13:497-512.

2. Levina V, Marrangoni AM, DeMarco R, Gorelik E, Lokshin AE. Drug-Selected Human Lung Cancer Stem Cells: Cytokine Network, Tumorigenic and Metastatic Properties. PloS one. 2008; 3.

3. Mao QC, Unadkat JD. Role of the breast cancer resistance protein (ABCG2) in drug transport. Aaps Journal. 2005; 7:E118-E133.

4. Mao QC, Unadkat JD. Role of the Breast Cancer Resistance Protein (BCRP/ABCG2) in Drug Transport-an Update. Aaps Journal. 2015; 17:65-82.

5. Salcido CD, Larochelle A, Taylor BJ, Dunbar CE, Varticovski L. Molecular characterisation of side population cells with cancer stem cell-like characteristics in small-cell lung cancer. Brit J Cancer. 2010; 102:1636-1644.

6. Summer R, Kotton DN, Sun X, Ma B, Fitzsimmons K, Fine A. Side population cells and Bcrp1 expression in lung. Am J Physiol-Lung C. 2003; 285:L97-L104.

7. Goodell MA, Brose K, Paradis G, Conner AS, Mulligan RC. Isolation and functional properties of murine hematopoietic stem cells that are replicating in vivo. Journal of Experimental Medicine. 1996; 183:1797-1806.

8. Ho MM, Ng AV, Lam S, Hung JY. Side population in human lung cancer cell lines and tumors is enriched with stem-like cancer cells. Cancer research. 2007; 67:4827-4833.

9. Wu C, Alman BA. Side population cells in human cancers. Cancer letters. 2008; 268:1-9.

10. Liu PP, Liao J, Tang ZJ, Wu WJ, Yang J, Zeng ZL, Hu Y, Wang P, Ju HQ, Xu RH, Huang P. Metabolic regulation of cancer cell side population by glucose through activation of the Akt pathway. Cell death and differentiation. 2014; 21:124-135.

11. Ota S, Ishii G, Goto K, Kubota K, Kim YH, Kojika M, Murata Y, Yamazaki M, Nishiwaki Y, Eguchi K, Ochiai A. Immunohistochemical expression of BCRP and ERCC1 in biopsy specimen predicts survival in advanced non-small- 
cell lung cancer treated with cisplatin-based chemotherapy. Lung cancer. 2009; 64:98-104.

12. Zhang K, Qi HX, Hu ZM, Chang YN, Shi ZM, Han XH, Han YW, Zhang RX, Zhang Z, Chen T, Hong W. YAP and TAZ Take Center Stage in Cancer. Biochemistry. 2015; 54:6555-6566.

13. Zhao B, Wei X, Li W, Udan RS, Yang Q, Kim J, Xie J, Ikenoue T, Yu J, Li L, Zheng P, Ye K, Chinnaiyan A, et al. Inactivation of YAP oncoprotein by the Hippo pathway is involved in cell contact inhibition and tissue growth control. Gene Dev. 2007; 21:2747-2761.

14. Zhao B, Ye X, Yu JD, Li L, Li WQ, Li SM, Yu JJ, Lin JD, Wang CY, Chinnaiyan AM, Lai ZC, Guan KL. TEAD mediates YAP-dependent gene induction and growth control. Gene Dev. 2008; 22:1962-1971.

15. Stein C, Bardet AF, Roma G, Bergling S, Clay I, Ruchti A, Agarinis C, Schmelzle T, Bouwmeester T, Schubeler D, Bauer A. YAP1 Exerts Its Transcriptional Control via TEAD-Mediated Activation of Enhancers. Plos Genet. $2015 ; 11$.

16. Harvey KF, Zhang XM, Thomas DM. The Hippo pathway and human cancer. Nat Rev Cancer. 2013; 13:246-257.

17. Zhao B, Tumaneng K, Guan KL. The Hippo pathway in organ size control, tissue regeneration and stem cell selfrenewal. Nat Cell Biol. 2011; 13:877-883.

18. Mo JS, Park HW, Guan KL. The Hippo signaling pathway in stem cell biology and cancer. Embo Rep. 2014; 15:642-656.

19. Lee JE, Park HS, Lee D, Yoo G, Kim T, Jeon H, Yeo MK, Lee CS, Moon JY, Jung SS, Kim JO, Kim SY, Park DI, et al. Hippo pathway effector YAP inhibition restores the sensitivity of EGFR-TKI in lung adenocarcinoma having primary or acquired EGFR-TKI resistance. Biochemical and biophysical research communications. 2016; 474:154-160.

20. Xiao L, Shi XY, Zhang Y, Zhu Y, Zhu L, Tian W, Zhu BK, Wei ZL. YAP induces cisplatin resistance through activation of autophagy in human ovarian carcinoma cells. OncoTargets and therapy. 2016; 9:1105-1114.

21. Ma K, Xu Q, Wang S, Zhang W, Liu M, Liang S, Zhu H, $\mathrm{Xu}$ N. Nuclear accumulation of Yes-Associated Protein (YAP) maintains the survival of doxorubicin-induced senescent cells by promoting survivin expression. Cancer letters. 2016; 375:84-91.

22. Dai XY, Zhuang LH, Wang DD, Zhou TY, Chang LL, Gai RH, Zhu DF, Yang B, Zhu H, He QJ. Nuclear translocation and activation of YAP by hypoxia contributes to the chemoresistance of SN38 in hepatocellular carcinoma cells. Oncotarget. 2016; 7:6933-6947. doi: 10.18632/ oncotarget.6903.

23. Zhang HB, Ramakrishnan SK, Triner D, Centofanti B, Maitra D, Gyorffy B, Sebolt-Leopold JS, Dame MK, Varani J, Brenner DE, Fearon ER, Omary MB, Shah YM. Tumorselective proteotoxicity of verteporfin inhibits colon cancer progression independently of YAP1. Sci Signal. 2015; 8.

24. Brodowska K, Al-Moujahed A, Marmalidou A, Horste MMZ, Cichy J, Miller JW, Gragoudas E, Vavvas DG. The clinically used photosensitizer Verteporfin (VP) inhibits YAP-TEAD and human retinoblastoma cell growth in vitro without light activation. Exp Eye Res. 2014; 124:67-73.

25. Gibault F, Corvaisier M, Bailly F, Huet G, Melnyk P, Cotelle P. Non-Photoinduced Biological Properties of Verteporfin. Current medicinal chemistry. 2016; 23:1171-1184.

26. Karthikeyan C, Malla R, Ashby CR, Jr., Amawi H, Abbott KL, Moore J, Chen J, Balch C, Lee C, Flannery PC, Trivedi P, Faridi J, Pondugula SR, et al. Pyrimido[1",2":1,5] pyrazolo[3,4-b]quinolines: Novel compounds that reverse ABCG2-mediated resistance in cancer cells. Cancer letters. 2016.

27. Tallarida RJ. An overview of drug combination analysis with isobolograms. The Journal of pharmacology and experimental therapeutics. 2006; 319:1-7.

28. Meng Z, Moroishi T, Guan KL. Mechanisms of Hippo pathway regulation. Genes Dev. 2016; 30:1-17.

29. Fujimoto D, Ueda Y, Hirono Y, Goi T and Yamaguchi A. PAR1 participates in the ability of multidrug resistance and tumorigenesis by controlling Hippo-YAP pathway. Oncotarget. 2015; 6:34788-34799. doi: 10.18632/ oncotarget.5858.

30. Vieyra DS, Rosen A, Goodell MA. Identification and characterization of side population cells in embryonic stem cell cultures. Stem cells and development. 2009; 18:1155-1166.

31. Chaffer CL, Brueckmann I, Scheel C, Kaestli AJ, Wiggins PA, Rodrigues LO, Brooks M, Reinhardt F, Su Y, Polyak K, Arendt LM, Kuperwasser C, Bierie B, et al. Normal and neoplastic nonstem cells can spontaneously convert to a stem-like state. Proceedings of the National Academy of Sciences of the United States of America. 2011; 108:7950-7955.

32. Lee SH, Kim H, Hwang JH, Lee HS, Cho JY, Yoon YS, Han HS. Breast cancer resistance protein expression is associated with early recurrence and decreased survival in resectable pancreatic cancer patients. Pathol Int. 2012; 62:167-175.

33. Stacy AE, Jansson PJ, Richardson DR. Molecular pharmacology of ABCG2 and its role in chemoresistance. Molecular pharmacology. 2013; 84:655-669.

34. Szakacs G, Paterson JK, Ludwig JA, Booth-Genthe C, Gottesman MM. Targeting multidrug resistance in cancer. Nat Rev Drug Discov. 2006; 5:219-234.

35. Tiwari AK, Sodani K, Dai CL, Ashby CR, Chen ZS, Chen ZS. Revisiting the ABCs of Multidrug Resistance in Cancer Chemotherapy. Curr Pharm Biotechno. 2011; 12:570-594.

36. Yoh K, Ishii G, Yokose T, Minegishi Y, Tsuta K, Goto K, Nishiwaki Y, Kodama T, Suga M, Ochiai A. Breast cancer resistance protein impacts clinical outcome in platinumbased chemotherapy for advanced non-small cell lung cancer. Clinical Cancer Research. 2004; 10:1691-1697.

37. Mao Q, Unadkat JD. Role of the breast cancer resistance protein $(\mathrm{BCRP} / \mathrm{ABCG} 2)$ in drug transport--an update. The AAPS journal. 2015; 17:65-82. 
38. Cheng H, Zhang Z, Rodriguez-Barrueco R, Borczuk A, Liu H, Yu J, Silva JM, Cheng SK, Perez-Soler R, Halmos B. Functional genomics screen identifies YAP1 as a key determinant to enhance treatment sensitivity in lung cancer cells. Oncotarget. 2016; 7:28976-88. doi: 10.18632/ oncotarget.6721.

39. Hsu PC, You B, Yang YL, Zhang WQ, Wang YC, Xu Z, Dai Y, Liu S, Yang CT, Li H, Hu B, Jablons DM, You L. YAP promotes erlotinib resistance in human non-small cell lung cancer cells. Oncotarget. 2016; 7:51922-51933. doi: 10.18632/oncotarget.10458.

40. Xia Y, Zhang YL, Yu C, Chang T, Fan HY. YAP/TEAD coactivator regulated pluripotency and chemoresistance in ovarian cancer initiated cells. PloS one. 2014; 9:e109575.

41. Wang C, Zhu X, Feng W, Yu Y, Jeong K, Guo W, Lu Y, Mills GB. Verteporfin inhibits YAP function through upregulating 14-3-3sigma sequestering YAP in the cytoplasm. American journal of cancer research. 2016; 6:27-37.

42. Donohue E, Balgi AD, Komatsu M, Roberge M. Induction of Covalently Crosslinked p62 Oligomers with Reduced Binding to Polyubiquitinated Proteins by the Autophagy Inhibitor Verteporfin. PloS one. 2014; 9.
43. Singh A, Wu HL, Zhang P, Happel C, Ma JF, Biswal S. Expression of ABCG2 (BCRP) Is Regulated by Nrf2 in Cancer Cells That Confers Side Population and Chemoresistance Phenotype. Molecular cancer therapeutics. 2010; 9:2365-2376.

44. Rosenfeldt MT, Bell LA, Long JS, O'Prey J, Nixon C, Roberts F, Dufes C, Ryan KM. E2F1 drives chemotherapeutic drug resistance via ABCG2. Oncogene. 2014; 33:4164-4172.

45. Singh RR, Kunkalla K, Qu C, Schlette E, Neelapu SS, Samaniego F, Vega F. ABCG2 is a direct transcriptional target of hedgehog signaling and involved in stromainduced drug tolerance in diffuse large B-cell lymphoma. Oncogene. 2011; 30:4874-4886.

46. Golebiewska A, Brons NH, Bjerkvig R, Niclou SP. Critical appraisal of the side population assay in stem cell and cancer stem cell research. Cell stem cell. 2011; 8:136-147.

47. Chou TC. Theoretical basis, experimental design, and computerized simulation of synergism and antagonism in drug combination studies. Pharmacological reviews. 2006; 58:621-681. 